三二九 錄驗實誌雜會究研事醫堂天順

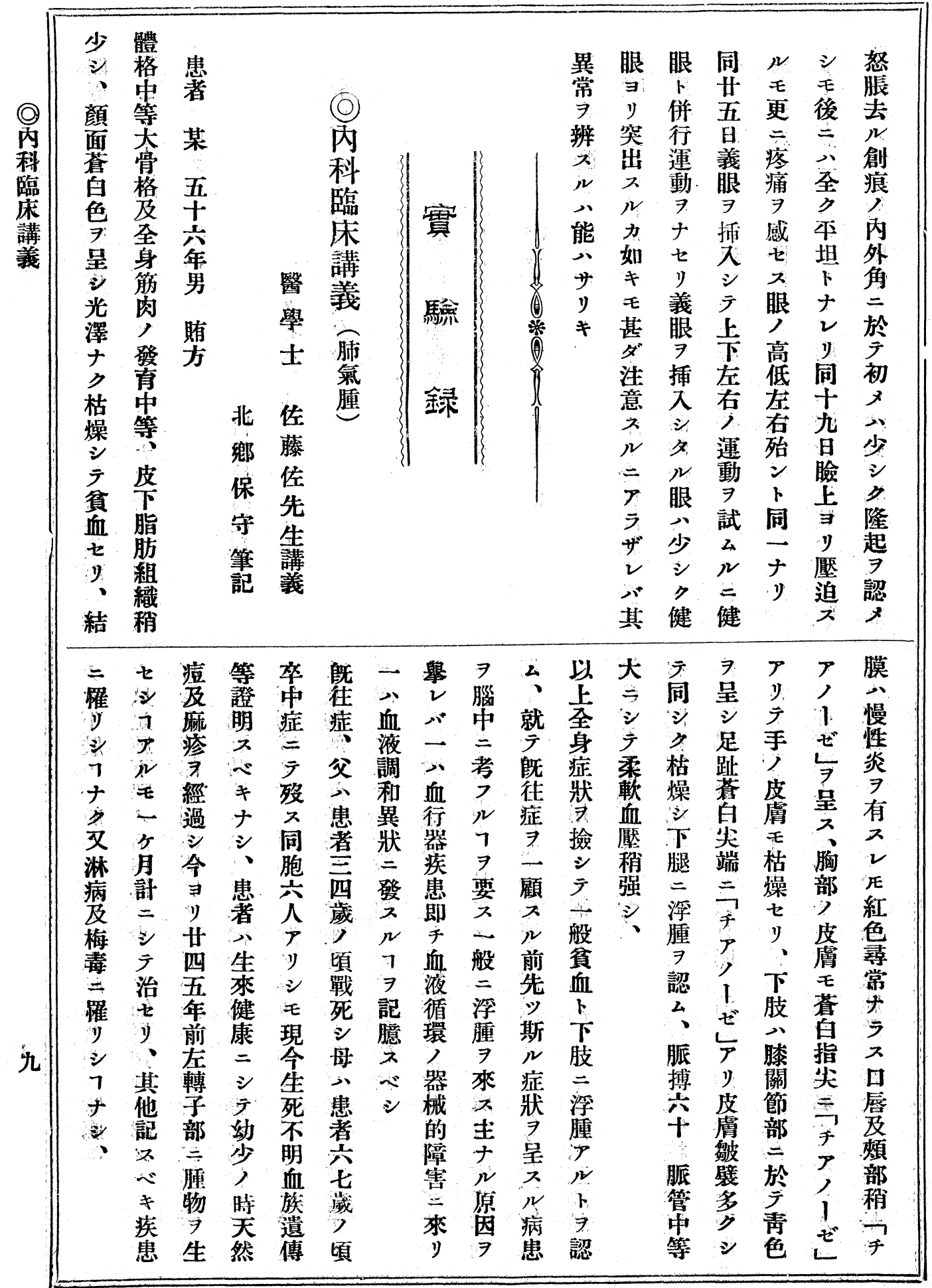


號二十三百三第誌雜會究研事醫堂天順四二九

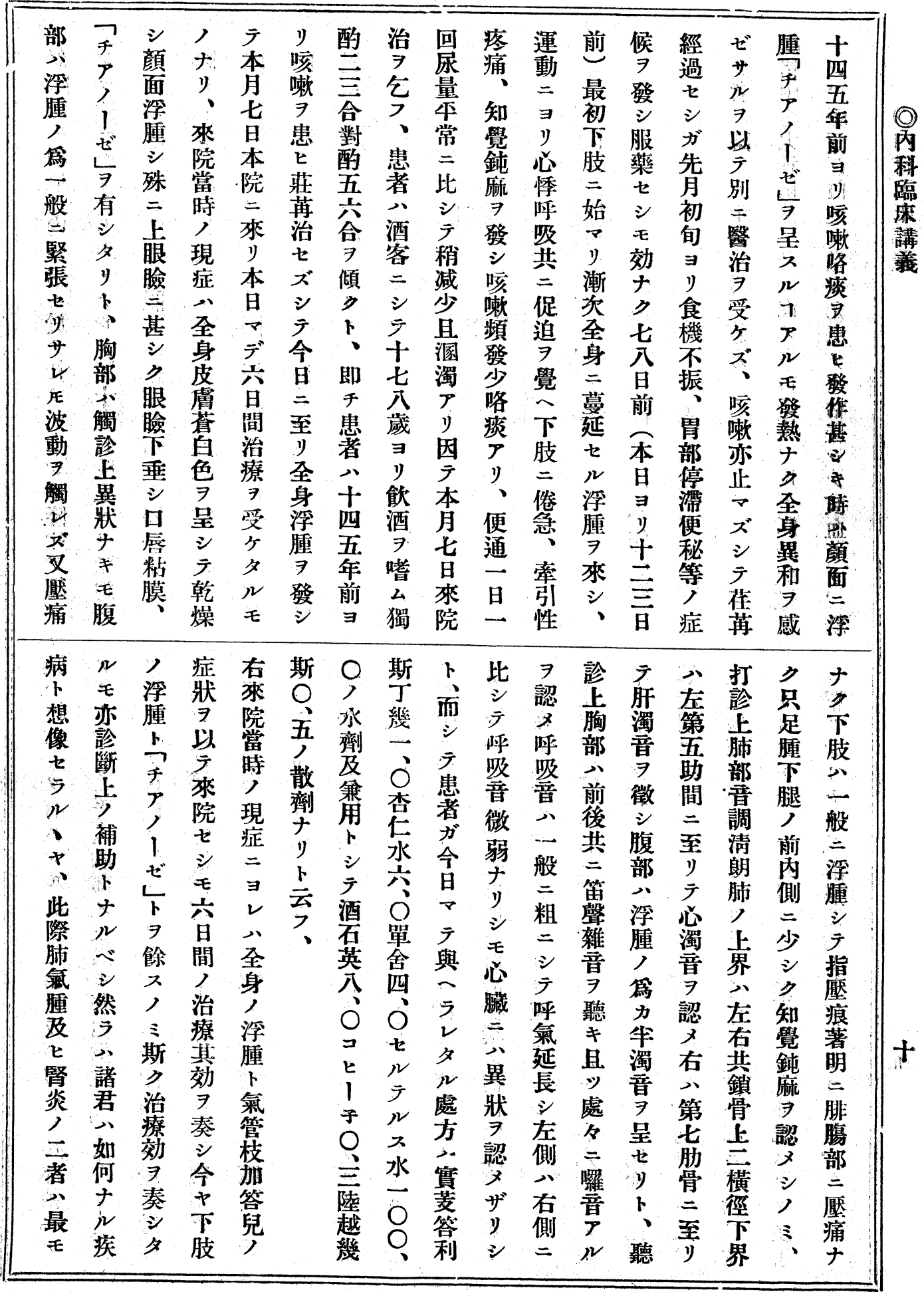


五二九 錄驗實誌雜會究研事醫堂天順

().

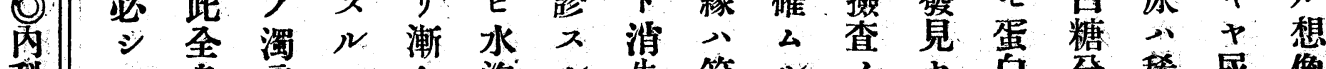

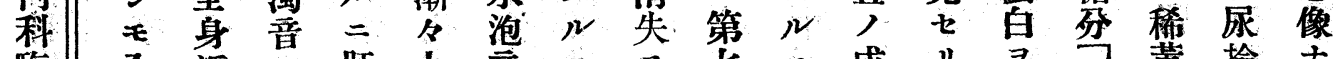

臨 全浮 $心$ 肝上音二

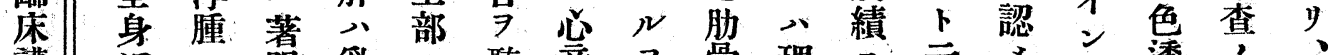

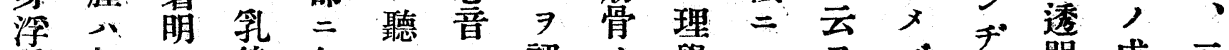

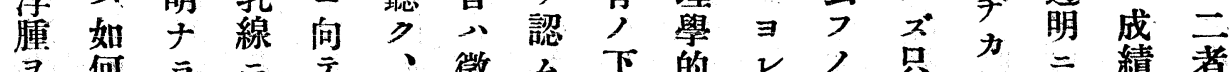

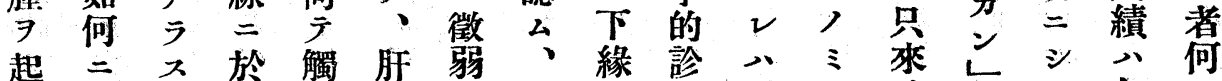

起

$E \bar{v}$ 肋法脾 $v$ 尖至 $\exists$ 炎 前痕惡何

> 發 $八$ 骨 $\exists$ 八

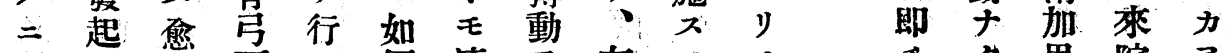

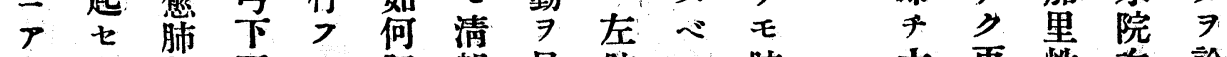

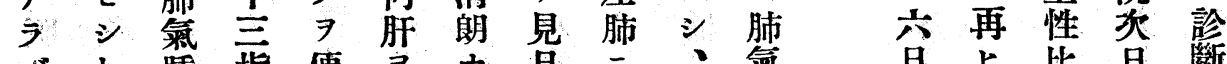

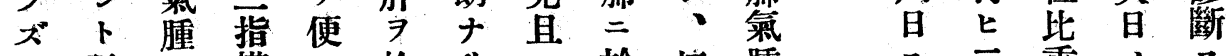

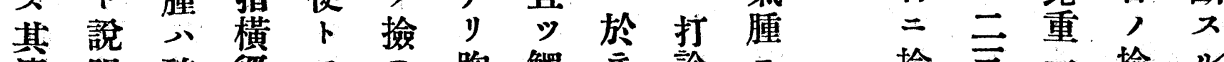

連明確 徑 $ス$ 實

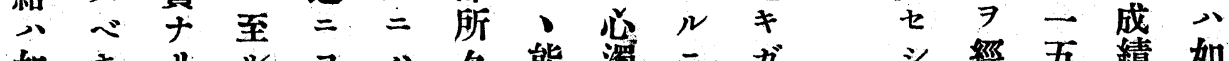

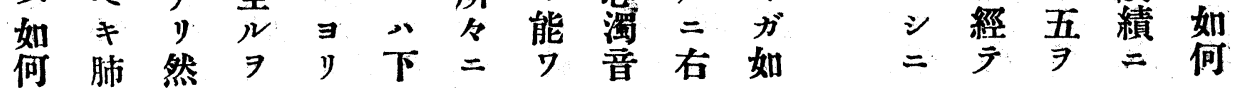

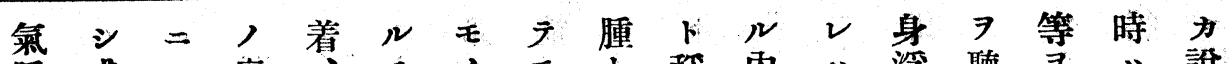
腫或 $シ$ 症售毛,

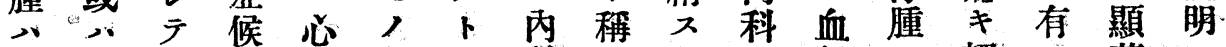

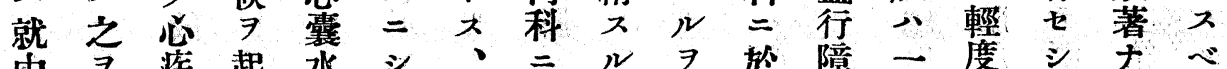

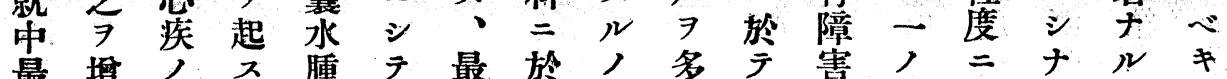

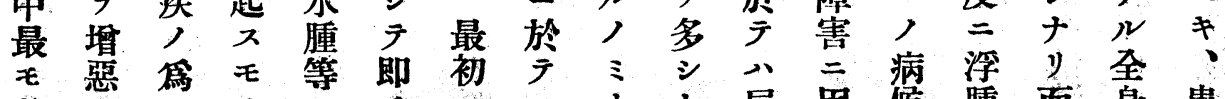

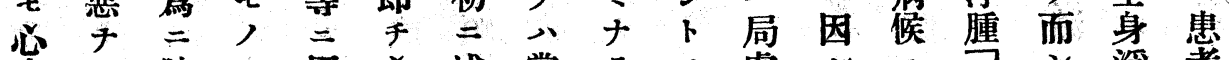

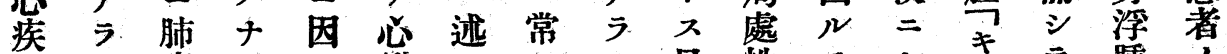

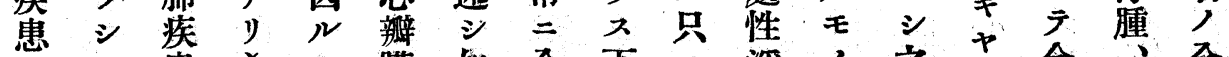

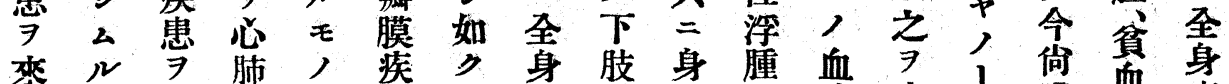

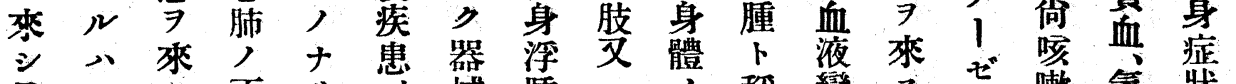

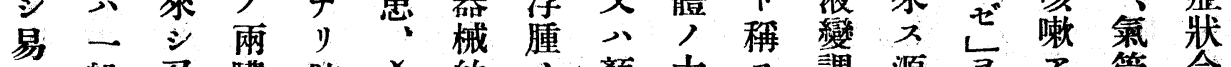

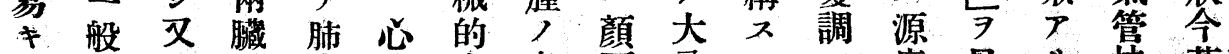
モ, 肺器 疾筋水考面分 $⿻$ 二 病見》枝著

\pm ）人疾 知篇簢亪性 血

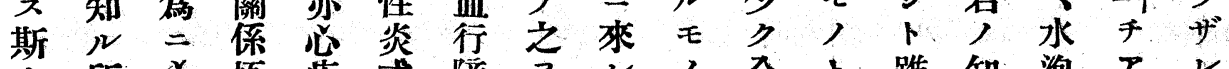
多 全

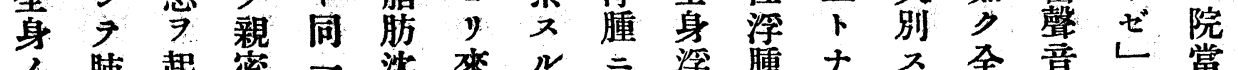
肺起密一沈來 $ン$ 浮腫ナス全音し當 
號二十三百三第誌雜會究研事醫堂天順 宍二九

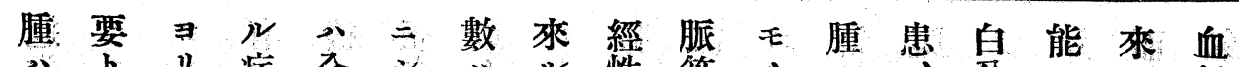

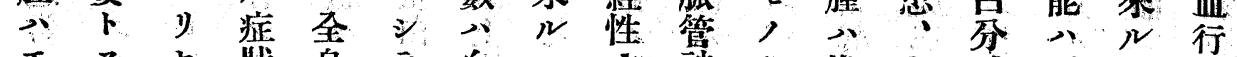

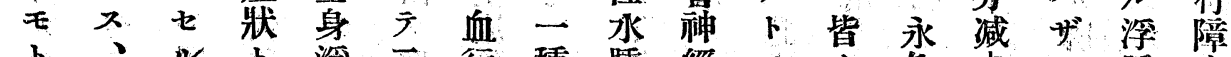

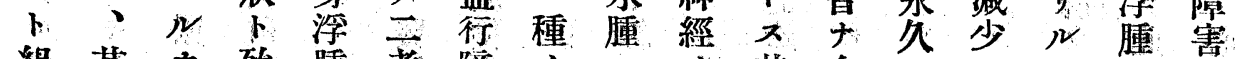

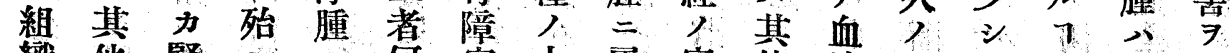

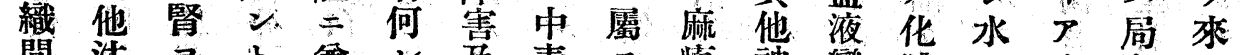
間洼 $、$ 意

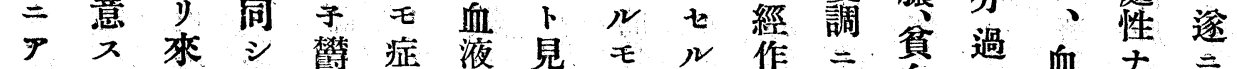

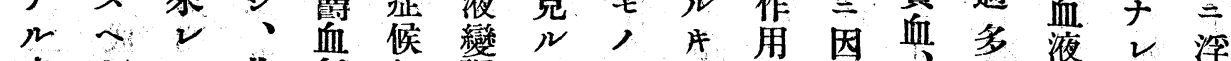
水

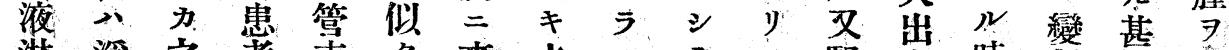

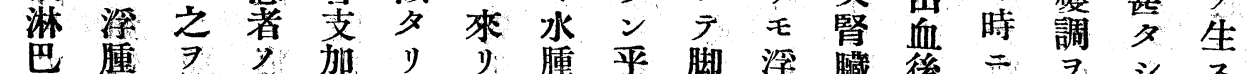

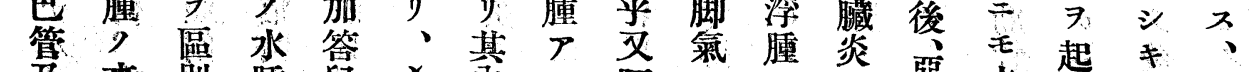

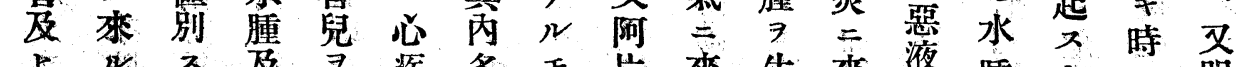

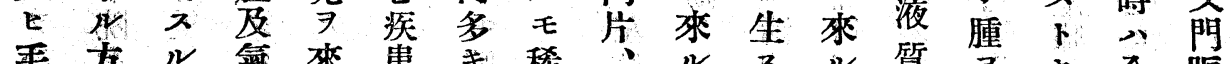

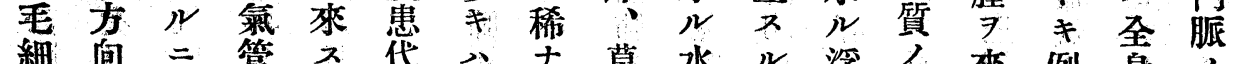

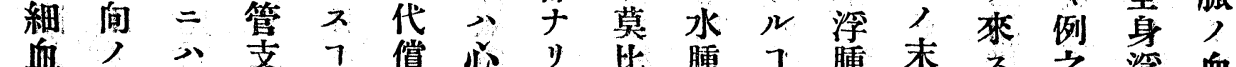

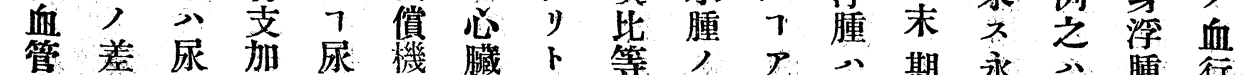
中 黑 撿 签 毒 7 病 $又$ 服 如 $y$ 特

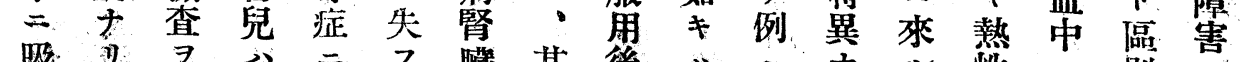

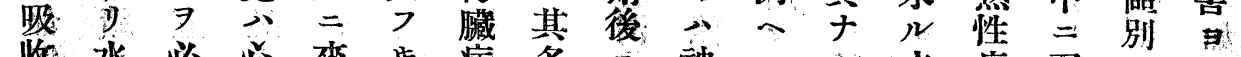

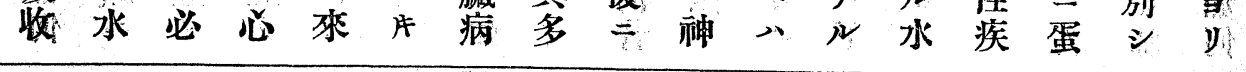

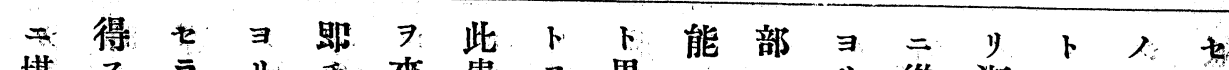

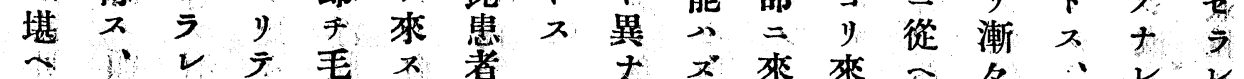

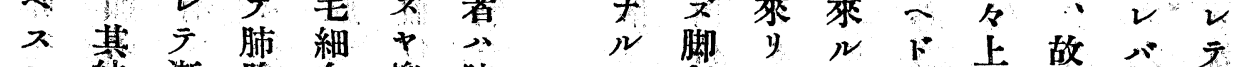

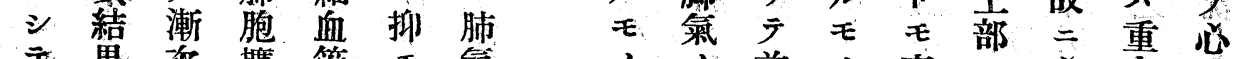
果次擴管王臷人前入高

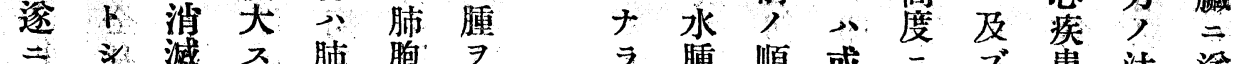
为 多右

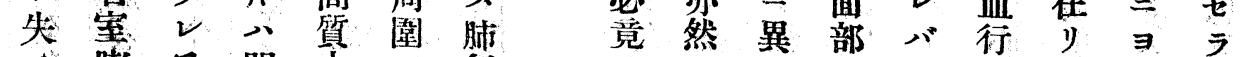

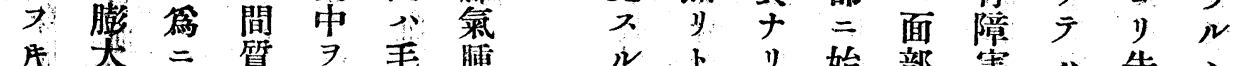

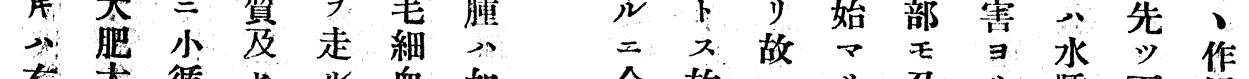

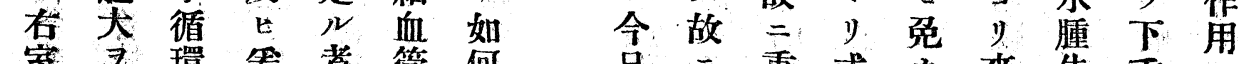

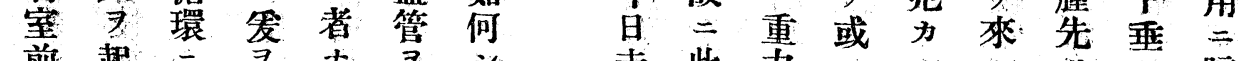

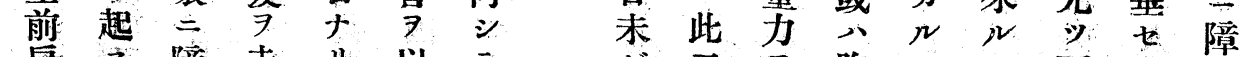
居齐障走 y 以

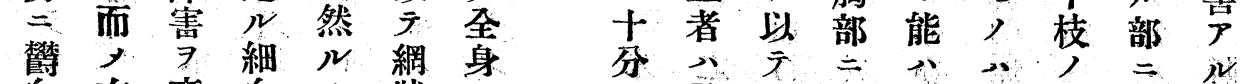

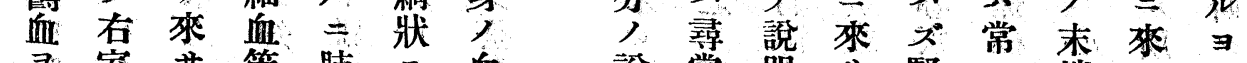
窒 サ 管 肺 血 說 常 明

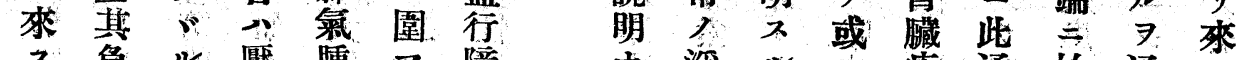
貢負 


\section{七二九 錄驗實誌雜會究研事醫堂天順}

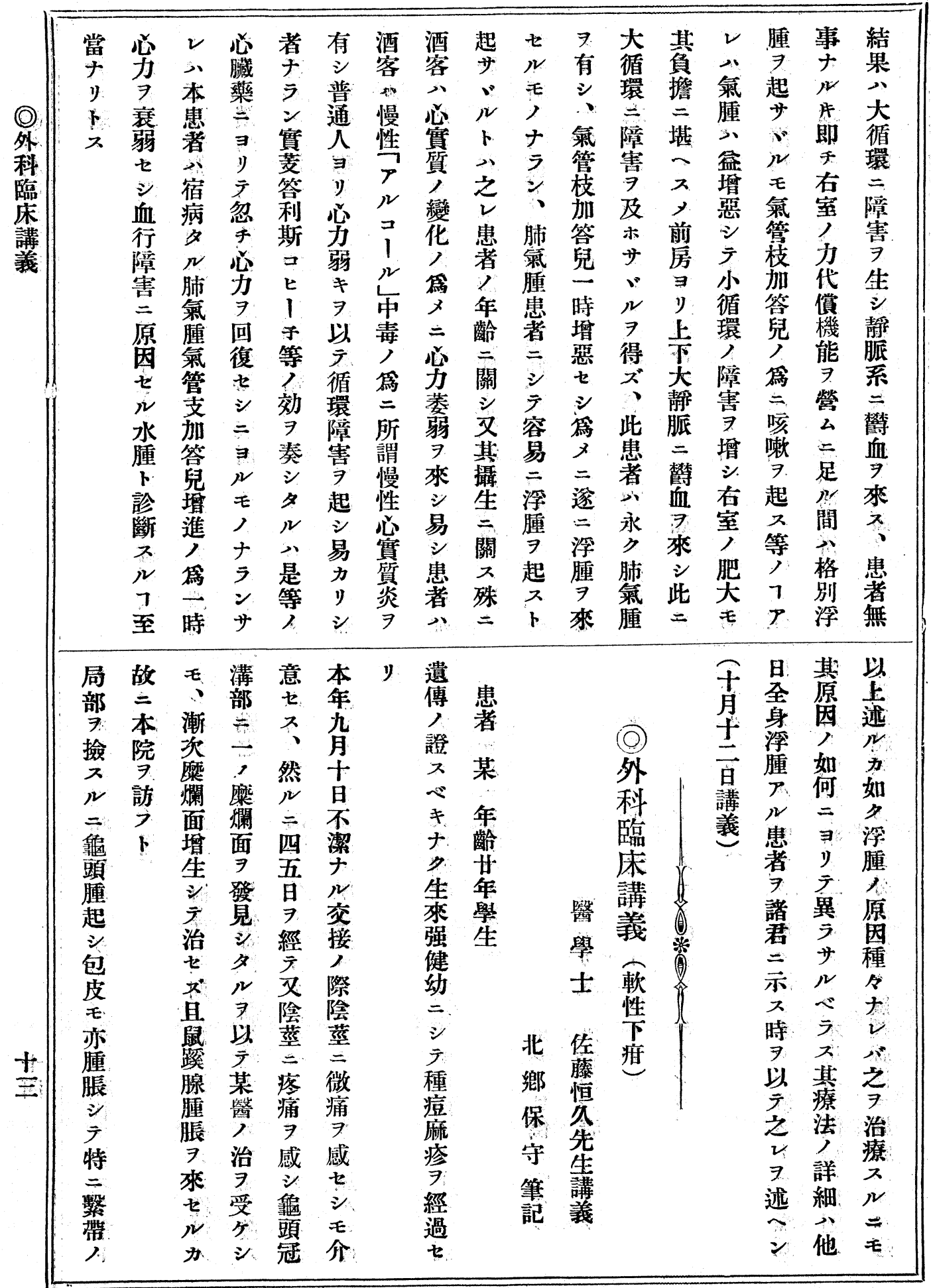

